\title{
Diversity of Sweepoviruses Infecting Sweet Potato in China
}

Qili Liu, Institute of Plant Protection, Henan Academy of Agricultural Sciences, Zhengzhou 450002, P. R. China; College of Plant Protection, China Agricultural University, Beijing 100193; and College of Resources \& Environmental Science, Henan Institute of Science and Technology, Xinxiang, P. R. China; Yongjiang Wang, Zhenchen Zhang ${ }^{\dagger}$, Hui Lv, Qi Qiao, Yanhong Qin, Desheng Zhang, Yuting Tian, and Shuang Wang, Institute of Plant Protection, Henan Academy of Agricultural Sciences; and IPM Key Laboratory in Southern Part of North China for Ministry of Agriculture, Zhengzhou 450002, P. R. China; and Jianqiang Li, College of Plant Protection, China Agricultural University, Beijing

\begin{abstract}
Sweepoviruses (a group of begomoviruses that infect plants in the family Convolvulaceae) have monopartite genomes that consist of a circular, single-stranded DNA molecule. Seventy-three complete genomic sequences of sweepoviruses were characterized from the sweet potato samples collected in China. Eight sweepovirus species, including two novel species with proposed names of Sweet potato leaf curl China virus 2 and Sweet potato leaf curl Sichuan virus 2, were identified among these samples. One species, Sweet potato leaf curl Canary virus, was first identified in China. Among the 13 identified strains of Chinese sweepoviruses, 4 were

newly discovered. Sweet potato leaf curl virus had the highest frequency (53.4\%) of occurrence in the sweet potato samples from China. The similarities among the 73 sweepovirus genomic sequences were between 77.6 and $100.0 \%$. Multiple recombination events were identified, and 16 recombinant sequences were determined. Recombination was observed between different species and between different strains of the same species. Recombination breakpoints were mainly localized on the intergenic region and in three open reading frames (AC1, AV1, and AV2). This study is the first comprehensive report on the genetic diversity of sweepoviruses in China.
\end{abstract}

Sweet potato, Ipomoea batatas (L.) Lam. (family Convolvulaceae), is an important food crop in developing countries (Clark et al. 2012). Most sweet potato crops produced in eastern Asia, $80 \%$ of which are produced in China (Anonymous 2007), the largest producer of sweet potato in the world (Tairo et al. 2005). Sweet potato is widely grown in China, and the following three major growing zones for sweet potato are distinguished according to their climatic conditions and cropping systems: the northern, Yangtze River, and southern regions (Gao et al. 2000; Ma et al. 2012; Xie et al. 2013; Zhang et al. 2009). Viral diseases can cause sweet potato yield losses and cultivar decline and are a major constraint in sweet potato production (Clark et al. 2002; Wang et al. 2010). In the United States, the yields from sweet potato cuttings infected with Sweet potato leaf curl virus (SPLCV) are reduced by 11 to $86 \%$, depending on the cultivar tested (Gibson and Kreuze 2015). Sweet potato plants are infected by over 30 viruses, including RNA and DNA viruses (Clark et al. 2012). Among these viruses, 11 were identified as begomoviruses (Adams et al. 2016; Zerbini et al. 2017).

Begomovirus is the largest genus in the family Geminiviridae and consists of $>320$ recognized species (Zerbini et al. 2017). Phylogenetic analysis showed that the begomoviruses further display a clear subdivision into four groups: Old World, New World, and the so-called "sweepoviruses" and "legumoviruses" (Zerbini et al. 2017). Sweepoviruses form a group (phylogenetically distinct from Old World and New World begomoviruses) that infects plants of the family Convolvulaceae, including sweet potato (Hassan et al. 2016). Genomes of sweepoviruses consist of approximately 2,800 nucleotides (nt) and encode two open reading frames (ORF) (AV1 and AV2) in the viralsense strand and four ORF (AC1 to AC4) in the complementary-sense strand (Lozano et al. 2009). Five species of sweepoviruses-namely,

${ }^{\dagger}$ Corresponding author: Z. Zhang; E-mail: zhangzhenchen@126.com

Q. Liu and Y. Wang are co-first authors.

*The $\boldsymbol{e}$-Xtra logo stands for "electronic extra" and indicates that one supplementary figure and thirteen supplementary tables are published online.

Accepted for publication 9 July 2017.

C 2017 The American Phytopathological Society
SPLCV, Sweet potato leaf curl China virus (SPLCCNV), Sweet potato leaf curl Georgia virus (SPLCGV), Sweet potato leaf curl Sichuan virus 1 (SPLCSiV-1), and Sweet potato leaf curl Henan virus (SPLCHnV) - were discovered in eight provinces of China (Bi and Zhang 2012; Chung et al. 1985; Liu et al. 2013, 2014; Luan et al. 2006; Qin et al. 2013; Tang et al. 2013).

The high genomic diversity of sweepoviruses was reported previously in some countries. For instance, Lozano et al. (2009) found five species of sweepoviruses in Spain and reported multiple recombination events that shaped the populations of Ipomoea-infecting begomoviruses. Ten genotypes of sweepoviruses exhibiting high genetic diversity (Zhang and Ling 2011) were reported in the United States (Mississippi and South Carolina). High diversity of sweet potato-associated geminiviruses (including two new species, three strains, and many variants of sweepoviruses) was found in 55 samples collected from a Brazilian germplasm bank (Paprotka et al. 2010). In 2012, three species, three novel strains, and 13 variants of sweepoviruses were reported in Brazil; thus, the genetic diversity was considerably greater than in the previous finding (Albuquerque et al. 2012).

In China, the diversity of sweepoviruses is not extensively investigated. Consequently, no foundation is available for disease control and prevention. Therefore, we studied the genetic diversity among sweepoviruses in sweet potato samples collected from 2010 to 2015 in China. We determined 73 complete genomic sequences using polymerase chain reaction (PCR) and rolling-circle amplification (RCA) methods. Variations of nucleic acid sequences, recombination events, and evolutionary relationships of the sweepoviruses in China were also investigated.

\section{Materials and Methods}

Collection of samples. From 2010 to $2015,>1,000$ sweet potato cuttings with virus-like symptoms were collected from 22 provinces in three major sweet-potato-growing regions in China (Fig. 1). Leaf samples were collected and stored at $-80^{\circ} \mathrm{C}$ until analysis.

Nucleic acid extraction. DNA was extracted from the leaf tissues of sweet potato using the universal genomic DNA extraction kit (TaKaRa) following the manufacturer's protocol. The extracted DNA was frozen at $-80^{\circ} \mathrm{C}$ until analysis.

Cloning and sequencing of the complete genome of sweepoviruses. PCR assays were conducted using three sets of begomovirus-universal primers: namely, BM-V/BM-C (Briddon and Markham 1994), 
PCRc1/PBL1v (Rojas et al. 1993), and Beta01/Beta02 (Gibson and Kreuze 2015) (Supplementary Table S1). The amplified PCR products were ligated to $\mathrm{pMD} 19-\mathrm{T}$ vector $(\mathrm{TaKaRa})$. The ligated product was transformed into an Escherichia coli competent cell (JM109), and the positive clones were sent to TaKaRa and Sangon Biotech for sequencing.

The DNA extracted from samples Guangxi5:2011 and Henan4: 2012 was amplified using the universal primers BM-V and BM-C, respectively. According to the determined sequence, two pairs of primers (GUI-11-5-1/GUI-11-5-2 and Henan-12-4-1/Henan-12-4-2) were designed to amplify the remaining part of the geminivirus genome. Complete sequences were obtained by splicing the two-part sequences.

RCA was implemented as described by Haible et al. (2006). Circular genomic DNA was amplified using an Illustra TempliPhi 100 Amplification kit (GE Healthcare) following the manufacturer's instructions. The amplified product $(1 \mu \mathrm{l})$ was digested in a $15-\mu l$ volume container with the restriction enzyme BamHI. The digested products were separated in a $0.8 \%$ agarose gel. The DNA fragments of the expected size $(2.8 \mathrm{~kb})$ were purified using an AxyPrep DNA Gel Extraction Kit (AXYGEN). The purified products were ligated into pUC118 vector (TaKaRa) digested with the corresponding restriction enzyme. The ligated product was transformed into $E$. coli competent cell and the positive clones were sequenced at TaKaRa and Sangon Biotech.

Sequence analysis. Nucleotide similarity searches of the National Center for Biotechnology Information database (https://www.ncbi. nlm.nih.gov/) were conducted using the Basic Local Alignment Search Tool (BLAST). The nucleotide identity percentages of the complete genome were compared with those of the closely related begomoviruses using the Sequence Demarcation Tool (SDT) program (http://web.cbio.uct.ac.za/ brejnev/) (Muhire et al. 2013). As recommended by the International Committee on Taxonomy of Viruses (ICTV) Geminiviridae Study Group, viruses with nucleotide identity of $<91 \%$ between full genome sequences were considered to be distinct species. If the sequence shared $<94 \%$ genome-wide pairwise identity with all isolates described for that species, then the isolates were considered to be distinct strains (Brown et al. 2015).

In addition to the full genomic sequences obtained in this study, 11 sequences representing sweepovirus species (Supplementary Table S2) and 33 relevant sequences (Supplementary Table S3) were available in public sequence databases (https://www.ncbi.nlm.nih.gov/) and were aligned using the SDT software (Muhire et al. 2013). Phylogenetic relationships were inferred with 1,000 bootstrap replicates, and evolutionary distances were calculated using the $P$ distance method implemented in the MEGA7 software (Sudhir et al. 2016).

Recombination analysis. In total, 117 sweepovirus sequences, including the 73 sequences obtained in this study, were selected and aligned using Muscle with default settings (Edgar 2004). Recombination events were screened using RDP, GENECOV, Bootscan, MaxChi, Chimaera, SiScan, and 3Seq methods implemented in the RDP4.77 program (Martin et al. 2010, 2015). We considered only the potential recombination events that were detected using the seven methods described above and involved fragments sharing $\geq 97 \%$ sequence identity with their parental sequences (Albuquerque et al. 2012).

\section{Results}

Species and molecular characteristics of sweepoviruses in China. Seventy-three complete sequences of sweepovirus were determined. The relevant information and accession numbers for the 73 sequences collected from different provinces in China are shown in Table 1. Using the ICTV guidelines of taxonomic criteria for the genus Begomovirus (Geminiviridae) and the SDT software with a species classification limit ( $91 \%$ nt sequence identity) for begomoviruses (Brown et al. 2015), 61 of 73 isolates were classified as isolates of six known species (Table 1): namely, SPLCV, SPLCCNV, SPLCGV, Sweet potato leaf curl Canary virus (SPLCCV), SPLCSiV-1, and SPLCHnV. The remaining 12 isolates had less than $91 \%$ sequence similarity with other known begomoviruses and belonged to new species (Supplementary Tables S4 and S5). Among these 12 sweepovirus isolates, 10 isolates (KF156759, KJ476509, KJ013573, KJ013574, KX033427, KX033437, KU992910, KX033422, KX033424, and KX073967) had 90.0 to $99.7 \%$ sequence similarity. KU992910 had 90\% sequence similarity with KX073967 but had $99.1 \%$ sequence similarity with KJ013574. Thus, these 10 isolates belonged to the same novel species with the proposed name Sweet potato leaf curl Sichuan virus 2 (SPLCSiV-2). This species was approved by ICTV (Adams et al. 2016). Two isolates (KJ476510 and KJ476508) had $96.4 \%$ nucleotide sequence similarity and thus belonged to the same novel species with the proposed name Sweet potato leaf curl China virus 2 (SPLCCNV-2).

Among these eight species found in China, SPLCCV was first discovered in sweet potato in China. Two species (SPLCCNV-2 and SPLCSiV-2) were novel sweepovirus species, and SPLCSiV-2 was approved and ratified by ICTV (Adams et al. 2016).

The 73 sweepovirus isolates from China possess similar gespecies. The sweepovirus genome comprised approximately $2,800 \mathrm{nt}$, from which two ORFs (AV1 and AV2) in the viral-sense strand and four ORFs (AC1-AC4) in the complementary-sense strand were predicted.

Based on distribution and frequency analyses, sweepoviruses were widely distributed in China and were detected in 11 provinces (Tables 1 and 2, Fig. 1). Seven sweepovirus species were found in Henan Province, whereas four and three sweepovirus species were

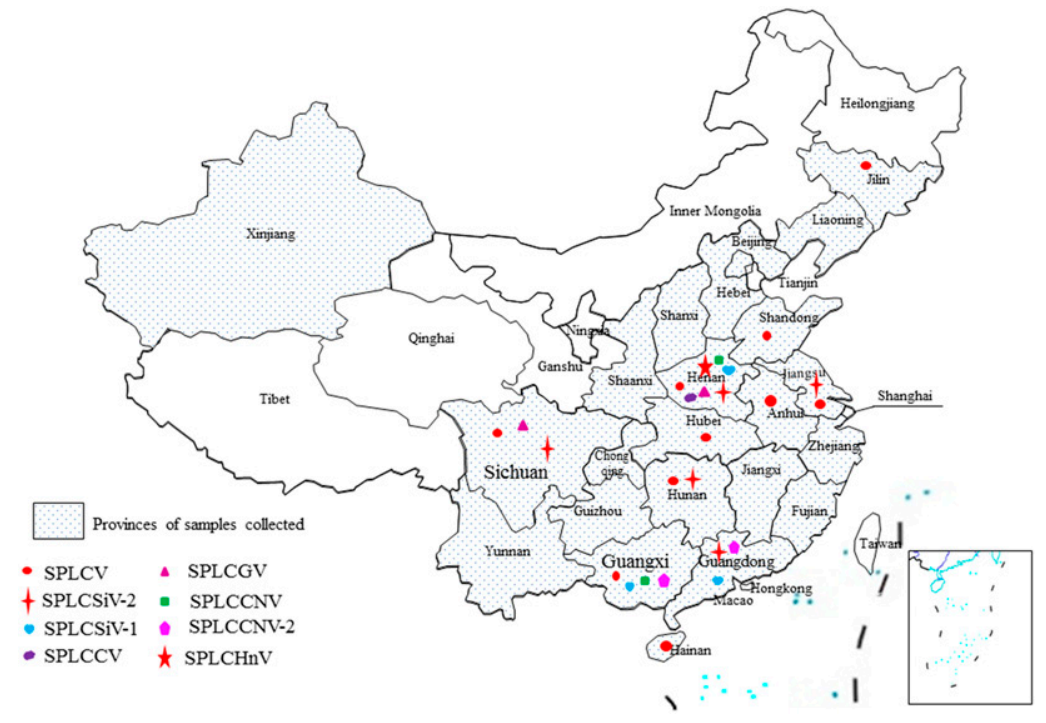

Fig. 1. Map of the provinces of samples collected and distribution of sweepoviruses species. 
Table 1. Information for 73 isolates of sweepoviruses collected in this study

\begin{tabular}{|c|c|c|c|c|}
\hline Species, strain ${ }^{a}$ & GenBank number & Isolate & Site in China (province, city) & Major symptoms \\
\hline \multicolumn{5}{|l|}{$\overline{\text { SPLCV }}$} \\
\hline \multirow[t]{10}{*}{ SPLCV-Sh } & KJ013577 & Anhui5:2012 & Anhui, Hefei & Leaf curl \\
\hline & KJ013578 & Hunan5:2012 & Hunan, Changsha & Leaf curl, mosaic \\
\hline & KF040467 & Jilin1:2012 & Jilin, Changchun & Leaf curl \\
\hline & KJ013579 & Jiangsu3-2-3:2010 & Jiangsu, Xuzhou & Leaf curl \\
\hline & KJ013580 & Jiangsu19:2010 & Jiangsu, Xuzhou & Leaf curl \\
\hline & KJ013581 & Hubei1:2012 & Hubei, Wuhan & Leaf curl, leaf shriveling \\
\hline & KP069466 & Shandong2:2014 & Shandong, Jinan & Leaf curl \\
\hline & KР069468 & Shandong4:2014 & Shandong, Jinan & Leaf curl \\
\hline & KX033444 & Zhengzhou62-19:2015 & Henan, Zhengzhou & Leaf curl, leaf shriveling \\
\hline & KX033446 & Yuanyang8:2015 & Henan, Yuanyang & Leaf curl, mosaic \\
\hline \multirow[t]{15}{*}{ SPLCV-Fu } & KJ013565 & Shandong11-2:2012 & Shandong, Weihai & Leaf curl, mosaic \\
\hline & KJ013555 & Henan20-1:2011 & Henan, Zhoukou & Chlorotic spots \\
\hline & KJ013556 & Henan26-1:2011 & Henan, Xinxiang & Fan-shaped leaves \\
\hline & KJ013559 & Guangxi5-2:2012 & Guangxi, Guigang & Leaf shriveling \\
\hline & KJ013560 & Guangxi9-1:2012 & Guangxi, Donxing & Leaf curl \\
\hline & KJ013562 & Guangxi3:2012 & Guangxi, Guigang & Leaf malformation \\
\hline & KJ013567 & Zhenghong7-1:2012 & Henan, Zhengzhou & Leaf malformation \\
\hline & KF040464 & Sichuan15(2):2012 & Sichuan, Chengdu & Mosaic, leaf shriveling \\
\hline & KF040466 & Shandong11:2012 & Shandong, Weihai & Leaf shriveling, leaf curl \\
\hline & KJ013570 & Henan26-2:2011 & Henan, Xinxiang & Leaf curl \\
\hline & KX033445 & Hainan12-22:2015 & Hainan, Sanya & Leaf curl, leaf malformation \\
\hline & KX033419 & Zhengzhou9-23:2015 & Henan, Zhengzhou & Leaf curl \\
\hline & KX033441 & Tanghe53-1:2015 & Henan, Tanghe & Leaf curl, vein yellowing \\
\hline & KP069465 & Shandong 1:2014 & Shandong, Jinan & Leaf curl \\
\hline & KX033434 & Zhengzhou68:2015 & Henan, Zhengzhou & Leaf curl, mosaic \\
\hline \multirow[t]{12}{*}{ SPLCV-US } & KF040465 & Henan25(8):2012 & Henan, Shangqiu & Vein yellowing, leaf malformation, stunting \\
\hline & KJ013582 & Sichuan16:2012 & Sichuan, Chengdu & Mosaic, vein yellowing, leaf malformation Fan shaped \\
\hline & KJ013566 & Anhui2:2012 & Anhui, Hefei & Leaf curl \\
\hline & KJ013557 & Sichuan6:2012 & Sichuan, Nanchong & Fan-shaped leaves, leaf malformation, stunting \\
\hline & KJ013568 & Anhui3:2012 & Anhui, Hefei & Leaf curl \\
\hline & KJ013569 & Henan3:2012 & Henan, Shangqiu & Leaf malformation, fan-shaped leaves \\
\hline & KJ013571 & Guangxi2:2012 & Guangxi, Fangchenggang & Chlorotic spots, leaf shriveling \\
\hline & KP069470 & Shandong7:2014 & Shandong, Jinan & Leaf curl \\
\hline & KP069471 & Shandong5:2014 & Shandong, Jinan & Leaf curl \\
\hline & KP069472 & Shandong8:2014 & Shandong, Sishui & Leaf curl \\
\hline & KX033421 & Zhengzhou11-22:2015 & Henan, Zhengzhou & Leaf curl \\
\hline & KX033438 & Zhengzhou24:2015 & Henan, Zhengzhou & Leaf curl, chlorotic spots \\
\hline \multirow[t]{2}{*}{ SPLCV-Hn ${ }^{\#}$} & KX033432 & Tanghe28-6:2015 & Henan, Tanghe & Leaf curl \\
\hline & KX056486 & Zhengzhou $37: 2015$ & Henan, Zhengzhou & Leaf curl \\
\hline \multicolumn{5}{|l|}{ SPLCGV } \\
\hline \multirow[t]{7}{*}{ SPLCGV-CN } & KJ013563 & Sichuan7:2012 & Sichuan, Nanchong & Mosaic \\
\hline & KX033418 & Zhengzhou9-21:2015 & Henan, Zhengzhou & Leaf curl \\
\hline & KX033420 & Zhengzhou10-11:2015 & Henan, Zhengzhou & Leaf curl, stunting \\
\hline & KX033436 & Hainan12-23:2015 & Henan, Zhengzhou & Leaf curl, mosaic \\
\hline & KX033431 & Zhengzhou25-34:2015 & Henan, Zhengzhou & Leaf curl \\
\hline & KX033429 & Zhengzhou31-10:2015 & Henan, Zhengzhou & Leaf curl, stunting \\
\hline & KX033442 & Zhengzhou36-5:2015 & Henan, Zhengzhou & Leaf curl \\
\hline \multirow[t]{2}{*}{ SPLCGV-US } & KX033433 & Yuanyang10:2015 & Henan, Yuanyang & Leaf curl, stunting \\
\hline & KX033423 & Yuanyang-11-3:2015 & Henan, Yuanyang & Leaf curl \\
\hline SPLCCNV & KJ013576 & Guangxi8:2012 & Guangxi, Guigang & Leaf curl \\
\hline & KX033439 & Zhengzhou44-10:2015 & Henan, Zhengzhou & Leaf malformation \\
\hline & KX033440 & Zhengzhou55-4:2015 & Henan, Zhengzhou & Leaf curl \\
\hline SPLCSiV-1 & KJ476511 & Guangxi(5-1):2012 & Guangxi, Guigang & Leaf curl, mosaic \\
\hline & KU992908 & Zhengzhou7:2015 & Henan, Xinxiang & Leaf curl \\
\hline & KX033425 & Yue5:2015 & Guangdong, Guangzhou & Leaf curl \\
\hline & KX033426 & Yue-15-5:2015 & Guangdong, Guangzhou & Leaf shriveling, leaf curl \\
\hline & KX033443 & Zhengzhou44-9:2015 & Henan, Xinxiang & Mosaic \\
\hline & KX033428 & Zhengzhou-15-64:2015 & Henan, Xinxiang & Mosaic \\
\hline SPLCHnV & KJ476507 & Henan10(2):2012 & Henan, Xinxiang & Leaf curl \\
\hline SPLCCNV-2* & KJ476510* & Guangxi5:2011 & Guangxi, Nanning & Leaf curl \\
\hline & KJ476508* & Yue32:2012 & Guangdong, Guangzhou & Leaf shriveling \\
\hline SPLCSiV-2* & & & & \\
\hline SPLCSiV-2-Sc ${ }^{\#}$ & KF156759* & Sichuan14:2012 & Sichuan, Nanchong & Leaf malformation \\
\hline & KJ476509* & Henan4:2012 & Henan, Shangqiu & Leaf curl \\
\hline & KJ013573* & Jiangsu3-2-2:2010 & Jiangsu, Xuzhou & Leaf malformation \\
\hline & KJ013574* & Hunan2:2012 & Hunan, Changsha & Leaf malformation, stunting \\
\hline & KX033427* & Yue-15-9:2015 & Guangdong, Guangzhou & Mosaic \\
\hline & KX033437* & Henanxihua-39:2015 & Henan, Xihua & Leaf shriveling \\
\hline & KU992910* & Zhengzhou52:2015 & Henan, Zhengzhou & Stunting, mosaic \\
\hline & KX033422* & Yuanyang-11-2:2015 & Henan, Yuanyang & Mosaic \\
\hline & KX033424* & Yuanyang-11-19:2015 & Henan, Yuanyang & Leaf shriveling \\
\hline SPLCSiV-2-Js ${ }^{\#}$ & KX073967* & SU-3-2:2015 & Jiangsu, Xuzhou & Stunting, leaf shriveling, mosaic \\
\hline SPLCCV & & & & \\
\hline SPLCCV-CN $\#$ & KX033435 & Tanghe26-8:2015 & Henan, Tanghe & Leaf shriveling, mosaic \\
\hline & KX033430 & Tanghe27-22:2015 & Henan, Tanghe & Leaf shriveling, chlorotic spots \\
\hline & KU992909 & Zhengzhou42:2015 & Henan, Zhengzhou & Leaf shriveling \\
\hline
\end{tabular}

\footnotetext{
${ }^{a}$ Full names of virus species and abbreviations: Sweet potato leaf curl Georgia virus (SPLCGV), Sweet potato leaf curl China virus (SPLCCNV), Sweet potato leaf curl virus (SPLCV), Sweet potato leaf curl Canary virus (SPLCCV), Sweet potato leaf curl Sichuan virus 1 (SPLCSiV-1), Sweet potato leaf curl Henan virus (SPLCHnV), Sweet potato leaf curl China virus 2 (SPLCCNV-2), and Sweet potato leaf curl Sichuan virus 2 (SPLCSiV-2); * indicates new species and \# indicates new strain.
} 
detected in Guangxi and Guangdong provinces, respectively. A single species was identified in Shandong, Anhui, Hainan, Jilin, and Hubei provinces. The species SPLCV had the highest frequency (53.4\%, Table 2) and was detected in 10 provinces, followed by SPLCSiV-2 (13.7\%) and SPLCGV (12.3\%). SPLCHnV had the least frequency $(1.4 \%)$ and was only detected in Henan Province.

Molecular variation and genetic diversity of sweepoviruses in China. BLAST analysis showed that these sweepovirus sequences were closely related to Old World begomoviruses. The similarities between the 73 sweepovirus genomic sequences were between 77.6 and $100.0 \%$ (Supplementary Table S4). The 73 isolates were classified into 13 strains according to the strain demarcation criteria for begomoviruses proposed by Brown et al. (2015). The species SPLCV consists of four strains, including a new one named "SPLCV-Hn" (Table 1, Supplementary Table S6). The species SPLCGV comprised two strains (Table 1, Supplementary Table S7). The 10 isolates of the new species SPLCSiV-2 are composed of two strains with the proposed names "SPLCSiV-2-Sc" and "SPLCSiV-2-JS" (Table 1, Supplementary Table S8). The three isolates of SPLCCV species from China had 99.8 to $99.9 \%$ sequence similarities and less than $94 \%$ similarity with the known isolates of SPLCCV. Thus, these isolates constitute a new strain named "SPLCCV-CN" (Supplementary Table S9). SPLCCNV, SPLCSiV-1, and SPLCHnV all have one strain based on the 94\% cut-off (Supplementary Table S10, S11, and S12). The phylogenetic relationships among the 73 sweepovirus isolates and other represented sweepovirus species are shown in Fig. 2. Based on the patterns of phylogenetic clustering depicted in the figure, the sweepoviruses in China were grouped into eight clades, namely, SPLCV, SPLCGV, SPLCCV, SPLCSiV-2, SPLCCNV, SPLCCNV-2, SPLCHnV, and SPLCSiV-1.

Recombination analysis of sweepoviruses in China. We analyzed the recombination in a 117 -sequence alignment, which includes the 73 full-length sweepoviruses described in this work, 11 sequences representing sweepovirus species, and 33 other relevant sequences. Frequent recombination events were detected in these sweepoviruses. Based on this analysis (using the seven statistical methods implemented in RDP software with high probability), the 117 isolates collectively bear 38 detectable recombination events, indicating that the recombinants were widespread across the 117 sequences (Supplementary Table S13). In considering only those potential recombination events that were detected using seven of the methods and have fragments that shared $\geq 97 \%$ sequence identity with their parental sequences, we determined 16 recombinant sequences belonging to six species (Table 3 ) in the final analysis. The SPLCV species had more recombinant isolates than other species. Recombination occurred between different species (interspecific recombination, such as between SPLCSiV-2 and SPLCV) or between different strains of the same species (intraspecific recombination, such as between SPLCV-Fu and SPLCV-Sh, SPLCV-Fu and SPLCV-US, and SPLCV-Sh and SPLCV-JP). In general, recombination breakpoints were mainly localized in the intergenic region (IR) and $\mathrm{AC} 1$, AV1, and AV2 ORF. Most of the recombination breakpoints were localized in the complementary sense genes. Specifically, SPLCSiV-2-Js (KX073967) was identified as a recombinant (between nucleotides 274 and 1,850) of SPLCSiV-2-Sc (KJ013573, 99.7\%) and SPLCVSh $(\mathrm{KJ} 013580,99.6 \%)\left(\right.$ range $P=1.243 \times 10^{-74}$ to $1.440 \times 10^{-11}$ ) (Table 3). SPLCCNV-2 (KJ476508) contains sequences derived through its recombination with SPLCV-Sh (EU309693, 98.8\%) and SPLCSiV-2-Sc (KX033424, 97.7\%) (range $P=8.751 \times 10^{-71}$ to $1.440 \times 10^{-11}$; nucleotides 1,887 to 57 ) (Table 3). SPLCSiV-2Sc (KF156759) contains sequences derived through its recombination

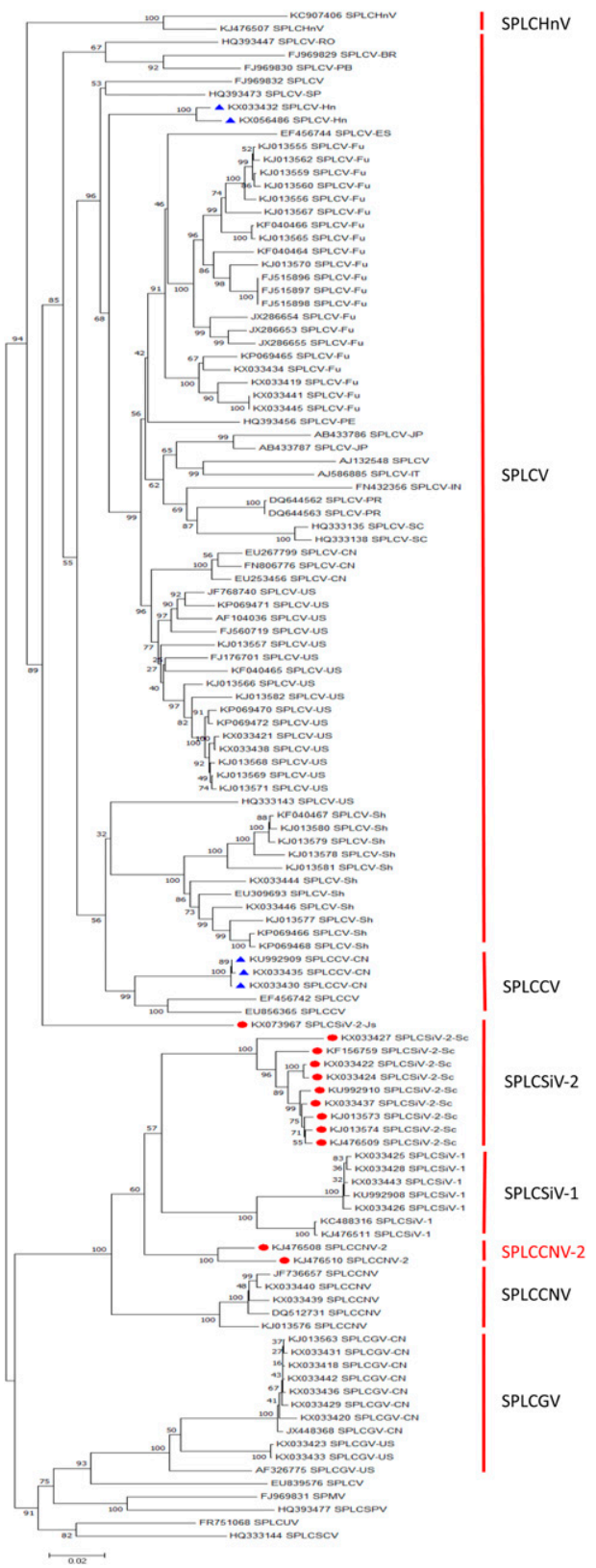

Fig. 2. Phylogenetic tree illustrating the relationships among 117 sweepoviruses sequences (new species and new strains are marked with a dot and triangle, respectively). The tree was constructed by the neighbor-joining method with 1,000 bootstrap replicates using MEGA7 software.

Table 2. Sweepoviruses species and frequencies of detection in this study

\begin{tabular}{lcl}
\hline Sweepoviruses & $\begin{array}{c}\text { Frequency (\%) } \\
\text { (isolates/total) }^{\mathbf{b}}\end{array}$ & \\
\hline Sweet potato leaf curl virus & $53.4(39 / 73)$ & Sichuan, Henan, Jiangsu, Shandong, Anhui, Guangxi, Hainan, Hunan, Jilin, Hubei \\
Sweet potato leaf curl Sichuan virus 2* & $13.7(10 / 73)$ & Sichuan, Henan, Jiangsu, Hunan, Guangdong \\
Sweet potato leaf curl Georgia virus & $12.3(9 / 73)$ & Sichuan, Henan \\
Sweet potato leaf curl Sichuan virus 1 & $8.2(6 / 73)$ & Guangxi, Henan, Guangdong \\
Sweet potato leaf curl Canary virus & $4.1(3 / 73)$ & Henan \\
Sweet potato leaf curl China virus & $4.1(3 / 73)$ & Guangxi, Henan \\
Sweet potato leaf curl China virus 2* & $2.7(2 / 73)$ & Guangdong, Guangxi \\
Sweet potato leaf curl Henan virus & $1.4(1 / 73)$ & Henan \\
\hline
\end{tabular}

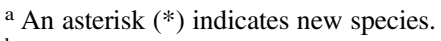

${ }^{\mathrm{b}}$ Number of isolates/total number of isolates.
} 
Table 3. Details of the recombination breakpoints detected in sweepoviruses

\begin{tabular}{|c|c|c|c|c|c|}
\hline Recombinant $^{\mathbf{a}}$ & Major parent ( $\%$ identity) & Minor parent (\% identity) & Breakpoints $^{\mathbf{b}}$ & Methods $\mathbf{c}$ & Range of $P$ value ${ }^{\mathrm{d}}$ \\
\hline KX073967* SPLCSiV-2-Js & KJ013573 SPLCSiV-2-Sc (99.7) & KJ013580 SPLCV-Sh (99.6) & 274 (AV2/AV1)-1,850 (AC1) & RGBMCST & $1.243 \times 10^{-74}$ to $1.440 \times 10^{-11}$ \\
\hline KJ476508* SPLCCNV-2 & KX033424 SPLCSiV-2-Sc (97.7) & EU309693 SPLCV-Sh (98.8) & 1,887 (IR)-57 (IR) & RGBMCST & $8.751 \times 10^{-71}$ to $1.440 \times 10^{-11}$ \\
\hline KJ476507 SPLCHnV & Unknown & KX033426 SPLCSiV-1 (99.5) & $2,023(\mathrm{AC} 1)-2,774(\mathrm{IR})$ & RGBMCST & $9.386 \times 10^{-55}$ to $1.440 \times 10^{-11}$ \\
\hline EF456742 SPLCCV & Unknown & EF456744 SPLCV-ES (97.8) & 2,721 (IR)-1,954 (AC1) & RGBMCST & $2.101 \times 10^{-63}$ to $8.388 \times 10^{-6}$ \\
\hline AB433786 SPLCV-JP & Unknown & AB433787 SPLCV-JP (99.6) & $2,832(\mathrm{IR})-2,241(\mathrm{AC} 1)$ & RGBMCST & $3.613 \times 10^{-27}$ to $1.067 \times 10^{-11}$ \\
\hline EU309693 SPLCV-Sh & KX033434 SPLCV-Fu (97.5) & KJ013581 SPLCV-Sh (97.8) & 1,038 (AV1)-2,824 (IR) & RGBMCST & $3.734 \times 10^{-54}$ to $7.698 \times 10^{-5}$ \\
\hline HQ333143 SPLCV-US & Unknown & AF104036 SPLCV-US (98.1) & 2,814 (IR)-2,097 (AC1) & RGBMCST & $7.662 \times 10^{-54}$ to $4.808 \times 10^{-9}$ \\
\hline HQ393447 SPLCV-RO & HQ393456 SPLCV-PE (98.8) & Unknown & 1,193 (AC3)-2,825 (IR) & RGBMCST & $1.005 \times 10^{-52}$ to $9.990 \times 10^{-8}$ \\
\hline KJ013578 SPLCV-Sh & Unknown & KJ013570 SPLCV-Fu (99.4) & 813 (AV1)-1,826 (IR) & RGBMCST & $1.353 \times 10^{-28}$ to $1.440 \times 10^{-11}$ \\
\hline EU839576 SPLCV & Unknown & EU856365 SPLCCV (97.8) & $2,132(\mathrm{AC} 1)-380(\mathrm{AV} 1 / \mathrm{AV} 2)$ & RGBMCST & $3.858 \times 10^{-48}$ to $4.504 \times 10^{-11}$ \\
\hline KJ476511 SPLCSiV-1 & Unknown & KU992910 SPLCSiV-2-Sc (98.3) & 1,070 (AC3)-1,787 (IR) & RGBMCST & $1.091 \times 10^{-42}$ to $6.323 \times 10^{-14}$ \\
\hline KF156759* SPLCSiV-2-Sc & KJ013574 SPLCSiV-2-Sc (99.3) & AF104036 SPLCV-US (98.9) & 732 (AV1)-1,005 (AV1) & RGBMCST & $6.902 \times 10^{-28}$ to $2.263 \times 10^{-6}$ \\
\hline KX033434 SPLCV-Fu & KX033445 SPLCV-Fu (98.9) & JF768740 SPLCV-US (99.9) & $62(\mathrm{IR})-750(\mathrm{AV} 1)$ & RGBMCST & $3.600 \times 10^{-26}$ to $8.370 \times 10^{-11}$ \\
\hline KX033446 SPLCV-Sh & KJ013580 SPLCV-Sh (97.5) & AB433787 SPLCV-JP (97.2) & $270(\mathrm{AV} 2)-812(\mathrm{AV} 1)$ & RGBMCST & $4.451 \times 10^{-16}$ to $1.916 \times 10^{-4}$ \\
\hline KX033424* SPLCSiV-2-Sc & KX033437 SPLCSiV-2-Sc (99.0) & KJ013581 SPLCV-Sh (98.4) & 42 (IR)-165 (AV2) & RGBMCST & $1.451 \times 10^{-19}$ to $3.767 \times 10^{-4}$ \\
\hline EU253456 SPLCV-CN & FN806776 SPLCV-CN (99.6) & Unknown & 2,428 (AC1/AC4)-2,752 (IR) & RGBMCST & $1.440 \times 10^{-11}$ to $5.029 \times 10^{-4}$ \\
\hline
\end{tabular}

a Only those potential recombination detected using seven methods in RDP 4.77 and involving fragments sharing $\geq 97 \%$ sequence identity with their parental sequences were considered. Virus species and abbreviations: Sweet potato leaf curl Georgia virus (SPLCGV), Sweet potato leaf curl China virus (SPLCCNV), Sweet potato leaf curl virus (SPLCV), Sweet potato leaf curl Canary virus (SPLCCV), Sweet potato leaf curl Sichuan virus 1 (SPLCSiV-1), Sweet potato leaf curl Henan virus (SPLCHnV), Sweet potato leaf curl China virus 2 (SPLCCNV-2), and Sweet potato leaf curl Sichuan virus 2 (SPLCSiV-2); an asterisk (*) indicates new species.

${ }^{\mathrm{b}}$ Beginning (open reading frame) to ending (open reading frame); IR = intergenic region.

${ }^{\mathrm{c}} \mathrm{R}, \mathrm{G}, \mathrm{B}, \mathrm{M}, \mathrm{C}, \mathrm{S}$, and T indicate detection by RDP, GENCONV, BOOTSCAN, MAXCHI, CHIMAERA, SISCAN, and 3SEQ methods, respectively, with the presented highest $P$ value being that determined by the method indicated in bold.

d Approximate range.

with SPLCSiV-2-Sc (KJ013574, 99.3\%) and SPLCV-US (AF104036, $98.9 \%$ ) (range $P=6.902 \times 10^{-28}$ to $2.263 \times 10^{-6}$; nucleotides 732 to 1,005) (Table 3). SPLCSiV-2-Sc (KX033424) was identified as a recombinant (between nucleotides 42 and 165) of SPLCSiV-2-Sc (KX033437, 99.0\%) and SPLCV-Sh (KJ013581, 98.4\%) (range $P=1.451 \times 10^{-19}$ to $\left.3.767 \times 10^{-4}\right)($ Table 3$)$.

\section{Discussion}

The species and distribution of sweepoviruses in China were identified and analyzed in this study. The sweepoviruses in China can be divided into eight species, among which two new species (SPLCCNV-2 and SPLCSiV-2) were identified. SPLCSiV-2 was approved and ratified by ICTV in April 2016 and was listed on the ICTV website (Adams et al. 2016). The SPLCCV species was first discovered in China. Among the 13 identified strains, 4 were newly found. SPLCV was a dominant species detected in 10 provinces. The phylogenetic tree showed that the 73 sweepoviruses collected from different parts of China were grouped into eight clades. The sweepoviruses in China had rich genetic inter- and intraspecific variations. To our knowledge, this study is the first comprehensive report on sweepoviruses in China.

Previous studies showed the high genetic diversity and recombination of sweepoviruses (Albuquerque et al. 2011, 2012; Lozano et al. 2009; Paprotka et al. 2010; Zhang and Ling 2011), which were similar to the results obtained in China. A high diversity indicates a high risk of evolution for many severe strains or species through recombination. Most recombination breakpoints were found during recombination events, which were mainly in the origin of replication (Zhang and Ling 2011) between AC2 and AC4 (Zhang and Ling 2011), in conjunction with predicted hairpin structures (Paprotka et al. 2010) or the IR, and in the middle of the AC1 ORF (Albuquerque et al. 2012). Our recombination analyses showed that the breakpoints of recombination mainly occurred in the IR and AC1, AV1, and AV2 ORF of sweepoviruses in China, which differed from those of sweepoviruses in the United States (IR and between AC2 and AC4) (Zhang and Ling 2011). The occurrence of natural recombination events may contribute to the appearance of many new sweepoviruses (Albuquerque et al. 2011; Liu et al. 2013, 2014; Zhang and Ling 2011). These phenomena suggested that virus monitoring should be strengthened to prevent and control the evolution of sweepoviruses.

Leaf curl, mosaic, and yellow leaves are the common symptoms for sweet potato infection by sweepoviruses (Albuquerque et al. 2012; Liu et al. 2013, 2014; Lozano et al. 2009; Luan et al. 2006; Paprotka et al. 2010; Qin et al. 2013; Tang et al. 2013; Zhang and
Ling 2011). In our research, the symptoms of sweepovirus-positive samples included leaf curl, mosaic, fan-shaped leaves, vein yellowing, chlorotic spots, leaf shriveling, leaf malformation, and stunting (Table 1). Approximately $60 \%$ of the sweepovirus-positive samples presented leaf curl, thus making this symptom an important diagnostic marker for sweet potato infection by sweepoviruses.

$\beta$-Satellite (previously known as DNA- $\beta$ ) is a circular, singlestranded DNA of approximately 1,350 nt that is associated with many monopartite begomoviruses and is essential for the induction of typical disease symptoms (Zhou 2013). $\beta$-Satellites depend on their helper viruses for replication, for cell-to-cell and systemic spread throughout the host, for encapsidation, and for transmission to new host plants via insect vectors (Zhou 2013). Swapna Geetanjali et al. found evidence of a natural association of two different $\beta$-satellites (CroYVMB and PaLCuB) with SPLCV in I. purpurea. The two different $\beta$-satellites were associated with leaf curl and yellow vein symptoms on the host plants (Swapna Geetanjali et al. 2013) Neither DNA-B nor $\beta$-satellite was detected from 530 DNA samples collected in China using specific primers for DNA-B or DNA- $\beta$ of begomoviruses. The sweepoviruses detected in the present study are monopartites and do not contain satellite molecules.

Understanding the diversity of viruses is important for preventing and controlling viral diseases. We extensively collected sweet potato samples in China and analyzed the species, distribution, and variation of sweepoviruses in these samples. A detailed knowledge of the diversity of viruses in sweet potato will help in devising future control measures.

\section{Acknowledgments}

This work was jointly supported by a grant from the Earmarked Fund for China Agriculture Research System (CARS-11-B-07) and the Science-Technology Foundation for Outstanding Young Scientists of Henan Academy of Agricultural Sciences (2016YQ14)

\section{Literature Cited}

Adams, M. J., Lefkowitz, E. J., King, A. M. Q., Balázs, H., Harrison, R. L., Knowles, N. J., Kropinski, A. M., Mart, K., Jens, H. K., Mushegian, A. R., Max, N., Sabanadzovic, S., Sanfaçon, H., Siddell, S. G., Simmonds, P., Varsani, A., Zerbini, F. M., Gorbalenya, A. E., and Andrew, J. D. 2016. Ratification vote on taxonomic proposals to the International Committee on Taxonomy of Viruses (2016). Arch. Virol. 161:2921-2949.

Albuquerque, L. C., Inoue-Nagata, A. K., Pinheiro, B., Resende, R. O., Moriones, E., and Navas-Castillo, J. 2012. Genetic diversity and recombination analysis of sweepoviruses from Brazil. Virol. J. 9:241.

Albuquerque, L. C., Inoue-Nagata, A. K., Pinheiro, B., Ribeiro, S. D. G., Resende, R. O., Moriones, E., and Navas-Castillo, J. 2011. A novel monopartite begomovirus infecting sweet potato in Brazil. Arch. Virol. 156:1291-1294. 
Anonymous. 2007. International Potato Center: World Sweetpotato Atlas. https:// research.cip.cgiar.org/confluence/display/WSA/Global+Sweetpotato+Cultivation

Bi, H.-P., and Zhang, P. 2012. Molecular characterization of two sweepoviruses from China and evaluation of the infectivity of cloned SPLCV-JS in Nicotiana benthamiana. Arch. Virol. 157:441-454.

Briddon, R. W., and Markham, P. G. 1994. Universal primers for the PCR amplification of dicot-infecting geminiviruses. Mol. Biotechnol. 1:202-205.

Brown, J. K., Murilo, Z. F., Navas-Castillo, J., Moriones, E., Ramos-Sobrinho, R., Silva, J. C. F., Fiallo-Olivé, E., Briddon, R. W., Hernández-Zepeda, C., Idris, A., Malathi, V. G., Martin, D. P., Rivera-Bustamante, R., Ueda, S., and Arvind, V. 2015. Revision of Begomovirus taxonomy based on pairwise sequence comparisons. Arch. Virol. 160:1593-1619.

Chung, M. L., Liao, C. H., Chen, M. J., and Chiu, R. J. 1985. The isolation transmission and host range of sweet potato leaf curl disease agent in Taiwan. Plant Prot. Bull. 27:333-341.

Clark, C. A., Davis, J. A., Abad, J. A., Cuellar, W., Fuentes, S., Kreuze, J., Gibson, R., Mukasa, S. B., Tugume, A. K., Tairo, F., and Valkonen, J. P. T. 2012. Sweet potato viruses: 15 Years of progress on understanding and managing complex diseases. Plant Dis. 96:168-185.

Clark, C. A., Valverde, R. A., Fuentes, S., Salazar, L. F., and Moyer, J. W. 2002. Research for improved management of sweetpotato pests and diseases: Cultivar decline. In: Proc. 1st Int. Conf. Sweetpotato, Food Health for the Future. T. Ames, ed. Lima, Peru. doi:10.17660/ActaHortic.2002.583.11

Edgar, R. C. 2004. MUSCLE: Multiple sequence alignment with high accuracy and high throughput. Nucleic Acids Res. 32:1792-1797.

Gao, F., Gong, Y., and Zhang, P. 2000. Production and employment of virus-free sweet potato in China. Crop Prot. 19:105-111.

Gibson, R. W., and Kreuze, J. F. 2015. Degeneration in sweetpotato due to viruses, virus-cleaned planting material and reversion: A review. Plant Pathol. 64:1-15.

Haible, D., Kober, S., and Jeske, H. 2006. Rolling circle amplification revolutionizes diagnosis and genomics of geminiviruses. J. Virol. Methods 135:9-16.

Hassan, I., Orílio, A. F., Fiallo-Olivé, E., Briddon, R. W., and Navas-Castillo, J. 2016. Infectivity, effects on helper viruses and whitefly transmission of the deltasatellites associated with sweepoviruses (genus Begomovirus, family Geminiviridae). Sci. Rep. 6: Article 30204. doi:10.1038/srep30204

Liu, Q.-L., Zhang, Z.-C., Li, J.-Q., Qiao, Q., Qin, Y.-H., Zhang, D.-S., Tian, Y.-T., Wang, S., and Wang, Y.-J. 2014. Complete genome sequence of a novel monopartite begomovirus infecting sweet potato in China. Arch. Virol. 159:1537-1540.

Liu, Q.-L., Zhang, Z.-C., Qiao, Q., Qin, Y.-H., Zhang, D.-S., Tian, Y.-T., Wang, S., and Wang, Y.-J. 2013. Complete genome sequence of a novel monopartite begomovirus infecting sweet potato in China. Virus Genes 47:591-594.

Lozano, G., Trenado, H. P., Valverde, R. A., and Navas-Castillo, J. 2009. Novel begomovirus species of recombinant nature in sweet potato (Ipomoea batatas) and Ipomoea indica: Taxonomic and phylogenetic implications. J. Gen. Virol. 90:2550-2562.

Luan, Y.-S., Zhang, J., and An, L.-J. 2006. First report of Sweet potato leaf curl virus in China. Plant Dis. 90:1111.

Ma, D.-F., Li, Q., Cao, Q.-H., Niu, F.-X., Xie, Y.-P., Tang, J., and Li, H.-M. 2012. Development and prospect of sweetpotato industry and its technologies in China. Jiangsu J. Agric. Sci. 28:969-973.
Martin, D. P., Lemey, P., Lott, M., Vincent, M., Posada, D., and Lefeuvre, P. 2010 RDP3: A flexible and fast computer program for analyzing recombination. Bioinformatics 26:2462-2463.

Martin, D. P., Murrell, B., Golden, M., Khoosal, A., and Muhire, B. 2015. RDP4 Detection and analysis of recombination patterns in virus genomes. Virus Evol. 1:1-5.

Muhire, B., Martin, D. P., Brown, J. K., Navas-Castillo, J., Moriones, E., Zerbini, F. M., Rivera-Bustamante, R., Malathi, V. G., Briddon, R. W., and Varsani, A. 2013. A genome-wide pairwise-identity-based proposal for the classification of viruses in the genus Mastrevirus (family Geminiviridae). Arch. Virol. 158: $1411-1424$

Paprotka, T., Boiteux, L. S., Fonseca, M. E. N., Resende, R. O., Jeske, H., Faria J. C., and Ribeiro, S. G. 2010. Genomic diversity of sweet potato geminiviruses in a Brazilian germplasm bank. Virus Res. 149:224-233.

Qin, Y.-H., Zhang, Z.-Z., Qiao, Z., Qiao, Q., Zhang, D.-S., Tian, Y.-T., and Wang, S. 2013. First report of Sweet potato leaf curl Georgia virus on sweet potato in China. Plant Dis. 97:1388.

Rojas, M. R., Gilbertson, R. L., and Russell, D. R. 1993. Use of degenerate primers in the polymerase chain-reaction to detect whitefly-transmitted geminiviruses. Plant Dis. 77:340-347.

Sudhir, K., Glen, S., and Koichiro, T. 2016. MEGA7: Molecular Evolutionary Genetics Analysis Version 7.0 for Bigger Datasets. Mol. Biol. Evol. 33:18701874.

Swapna Geetanjali, A., Shilpi, S., and Mandal, B. 2013. Natural association of two different betasatellites with Sweet potato leaf curl virus in wild morning glory (Ipomoea purpurea) in India. Virus Genes 47:184-188.

Tairo, F., Mukasa, S. B., Jones, R. A. C., Kullaya, A., and Valkonen, J. P. T. 2005 Unravelling the genetic diversity of the three main viruses involved in sweet potato virus disease (SPVD), and its practical implications. Mol. Plant Pathol. 6:199-211.

Tang, Y.-F., He, Z.-F., Han, L.-F., and Luo, F.-F. 2013. Molecular detection and identification of Sweet potato curl leaf virus infecting sweet potato in Guangdong Province. Plant Prot. 39:25-28. (In Chinese)

Wang, Q. M., Zhang, L. M., Wang, B., Yin, Z. F., Feng, C. H., and Wang, Q. C. 2010. Sweetpotato viruses in China. Crop Prot. 29:110-114.

Xie, Y. P., Xing, J. Y., Li, X. Y., Wang, X., Sun, H. J., Zhao, Y. Q., Zhang, C. L., and Ma, D. F. 2013. Survey of sweetpotato viruses in China. Acta Virol. 57: 81-84

Zerbini, F. M., Briddon, R. W., Idris, A., Martin, D. P., Moriones, E., NavasCastillo, J., Rivera-Bustamante, R., Roumagnac, P., and Varsani, A., and ICTV Report Consortium. 2017. ICTV Virus Taxonomy Profiles: Geminiviridae J. Gen. Virol. 98:131-133.

Zhang, L. M., Wang, Q. M., Liu, Q. C., and Wang, Q. C. 2009. Sweetpotato in China. Pages 325-358 in: Biology and Biotechnology of Sweetpotato. G. Loebenstain and G. Thottappilly, eds. Springer Netherlands, Heidelberg, Germany.

Zhang, S. C., and Ling, K. S. 2011. Genetic diversity of sweet potato begomoviruses in the United States and identification of a natural recom binant between Sweet potato leaf curl virus and Sweet potato leaf curl Georgia virus. Arch. Virol. 156:955-968.

Zhou, X. 2013. Advances in understanding begomovirus satellites. Annu. Rev. Phytopathol. 51:357-381 